\title{
Specific damage recognised on land snail shells as a tool for studying predation intensity: differences related to habitat and predator types
}

\author{
Tomáš Němec \\ Department of Botany and Zoology, Masaryk University, Kotlářská 2, CZ-611 37 Brno, Czech \\ Republic \\ neme.tomik@seznam.cz \\ Michal Horsák \\ Department of Botany and Zoology, Masaryk University, Kotlářská 2, CZ-611 37 Brno, Czech \\ Republic \\ horsak@sci.muni.cz
}

\begin{abstract}
Shell formation is the main defensive strategy against predation for the majority of snails. Therefore, various predators have had to develop a variety of techniques how to overcome this barrier. As shells can persist in a calcium-rich environment for a long time, specific external or internal traces on shells left by predators indicate whether and who killed the snail. Based on litter samples collected at 30 sites of five different habitat types, the intensity and type of predation were assessed. The minimal predation rate varied between 0.0 and $21 \%$, with an average of $8 \%$. The highest rate was observed at limestone steppes, on average $15 \%$. Beetles were found to be the most common predators of snails; however, predation by snails was more common in calcareous fens. Predation by some vertebrates and dipteran flies was also recognised. To test the role of mouth barriers as a means to reduce predation by carabid beetles that break the shell from an aperture, we analysed the predation rate separately on adult and juvenile shells using 24 populations of the steppe snail Granaria frumentum (Draparnaud, 1801). As expected, carabid beetles chiefly preferred juveniles compared to adult shells (Wilcoxon test, $\mathrm{p}<0.001$ ). On the contrary, the parasitoid fly Pherbellia limbata (Meigen, 1830) and Drilus beetles preferred adults. We found that predation by carabid beetles positively increased with prey abundance $\left(\mathrm{R}^{2}=42.8 \%, \mathrm{p}=0.021\right)$, while no relation was observed for the parasitoid $(\mathrm{p}=0.703)$, likely due to their feeding specialisation.
\end{abstract}

\section{Keywords}

attacking behaviour - competition - predation - prey - shell damage - snail

(C) NĚMEC \& HORSÁK, 2019 | DOI:10.1163/18759866-20191402

This is an open access article distributed under the terms of the CC-BY 4.0 License. 


\section{Introduction}

Land snail communities of temperate and boreal zones are well known to be driven by several ecological gradients, mainly related to the calcium level (Wäreborn, 1970; Hylander et al., 2005; Juřičková et al., 2008), soil moisture and architecture (Wäreborn, 1992; Nekola, 2003; Hettenbergerová et al., 2013) and habitat history (Cameron et al., 1980; Kappes, 2006; Horsák et al., 2012). Additionally, the effect of macroclimate (Horsák et al., 2013a; Nicolai \& Ansart, 2017; Horsák et al., 2018) and the existence of shelters to overwinter (Millar \& Waite, 1999; Ansart et al., 2001; Horsák et al., 2015) have been found to be important. Although we know a good amount about the bottom-up limitation of snail communities, little is known about top-down mechanisms constituted by snail predators, pathogens, and other natural enemies (see Barker, 2004). A high importance of biotic interactions can be expected because land snails may provide suitable sources of water to many predators, especially in arid conditions (Yom-Tov, 1970; Shachak et al., 1981), as well as energy and nutrients, including calcium (Graveland \& van Gijzen, 1994). Furthermore, snails can rasp parts of each other's shells in calcium poor environments (Fournié \& Chétail, 1984).

There is an extensive body of literature on natural enemies of land snails (see Barker, 2004 for the most recent review), among which several beetle families, particularly carabids, were identified as the most common predators of land snails (e.g., Konuma et al., 2011; Baalbergen et al., 2014). In the case of snail-killing carabid beetles, two types of feeding specialisation have evolved in two mutually exclusive directions, i.e., crawling into the shell (cychrisation) and breaking the shell apart (procerisation). Individual predators are morphologically adapted to one of these strategies (Thiele, 1977). Besides beetles, dipteran flies represent another known gastropod predators, often also as parasitoids. Species of the family Sciomyzidae are best known for their development associated with molluscs (Vala et al., 2000; Knutson \& Vala, 2011). However, for most dipteran fly larvae it is difficult to determine their exact feeding relationship to molluscs, as they can fit to a saprophage, parasite, parasitoid or predator strategy. Importantly, some snails are also known to be carnivorous with clear preferences for other snails (Mordan, 1977; Griffiths et al., 1993; Barker \& Efford, 2004; Myzyk, 2014). In addition, aggressive behaviour and cannibalism are well-known in predators among land snails (Baur, 1992). Several other invertebrate groups such as harvestmen (Nyffeler \& Symondson, 2001) and terrestrial flatworms (Ogren \& Sheldon, 1991; Sugiura et al., 2006), as well as many vertebrates such as small mammals (e.g., Rosin et al., 2011), birds (e.g., Shachak et al., 1981), and reptiles (e.g., Hoso et al., 2010) are among the common consumers of land snails. It is generally assumed that the number of malacophagous vertebrates is smaller in comparison with the number of vertebrates targeting other groups of animals (e.g., insects). Based on a large number of various malacophagous predators, it is clear that predation must have important regulatory effects on land snail communities, although there have been virtually no studies that have attempted to quantify this intensity using any method (but see Millar \& Waite, 1999).

There are several commonly used approaches regarding how to detect predation such as analyses of (i) prey remains in a predator digestive system or its faeces (e.g., Griffiths et al., 1993; Hoso \& Hori, 2006), (ii) stable isotopes of nitrogen and carbon to investigate dietary specialisation (e.g., Meyer \& Yeung, 2011; Yanes et al., 2018), and (iii) DNA fragments in the predator intestine (Harper et al., 2005; Eskelson et al., 2011). However, using all these 
methods it is difficult to quantify the level of predation in natural communities. For land snails, there is a unique opportunity to retrospectively reconstruct a level of predation by the analysis of external and internal damage recognised on their empty shells. In a calcium rich environment, empty shells accumulating over several years (Říhová et al., 2018) provide an excellent record about the level of predation on land snail communities. As the types of shell damage made by various predators are well-described (e.g., Goodhart, 1958; YomTov, 1970; Quensen \& Woodruff, 1997; Chiba, 2007; Meyer \& Shiels, 2009; Rosin et al., 2011; Baalbergen et al., 2014; Myzyk, 2014), we can easily and relatively accurately partition predation pressure among various groups of predators (see Millar \& Waite, 2004). Although some predators do not damage shells, they do leave specific marks of their predation activity within the shell. These include for example larvae exuviae of predatory beetles of the genus Drilus (Baalbergen et al., 2014) and the puparia of parasitoid flies such as Pherbellia limbata (Nerudová-Horsáková et al., 2016). Additionally, the developmental stage of an individual victim can also be recognised based on the empty shell, which enables us to observe predator preferences for juveniles or adults of the prey species. Because some predators attack the snail through the shell mouth, leaving the victim's shell undamaged, the predator pressure assessed by the above introduced approach needs to be viewed as minimal.

Despite a unique opportunity to assess predation pressure by using the analysis of specific damage in empty shells, this approach has been used very rarely. So far, there has been only a single study using damage recognised on empty shells and exploring predation made by various predators based on samples collected in a single forest site in England (Millar \& Waite, 2004). To the best of our knowledge, there has been no study assessing predation intensity based on samples collected from a larger number of sites across a large area and comparing differences among various predators and habitat types.

Thus, the main goal of this study was to provide the first quantitative data on the intensity of predation on land snail communities sampled across many sites, stratified into five types of temperate habitat: talus forests, floodplain forests, wet meadows, calcareous fens, and limestone steppes. Secondly, we also aimed to investigate predation intensity in relationship to population densities and development stages of the steppe snail Granaria frumentum, a snail prey with a strongly armed aperture in the adult stage. We tested whether there were any differences in the minimal rate of predation and frequency of predator types among the studied habitat types. For populations of G. frumentum, we hypothesised a higher rate of predation by carabid beetles on juvenile stages in contrast to adult shells which are protected by a strong mouth incrustation. We also tested whether the predation rate is correlated to prey abundance for both true predators (i.e., carabid beetles) and parasitoid species (i.e., the fly $P$. limbata). We expected a positive association for true predators, but there was not a clear prediction made on a possible pattern for the parasitoid.

\section{Materials and methods}

\section{Study sites and data collection}

Samples were collected between 2015 and 2018. The study sites were selected based on an extensive previous survey of snail assemblages by the senior author in various habitat types across southern Moravia (Czechia) and Slovakia (fig. 1). To explore the predation rate and its relation to habitat types, six site replicates were sampled for each of the five 


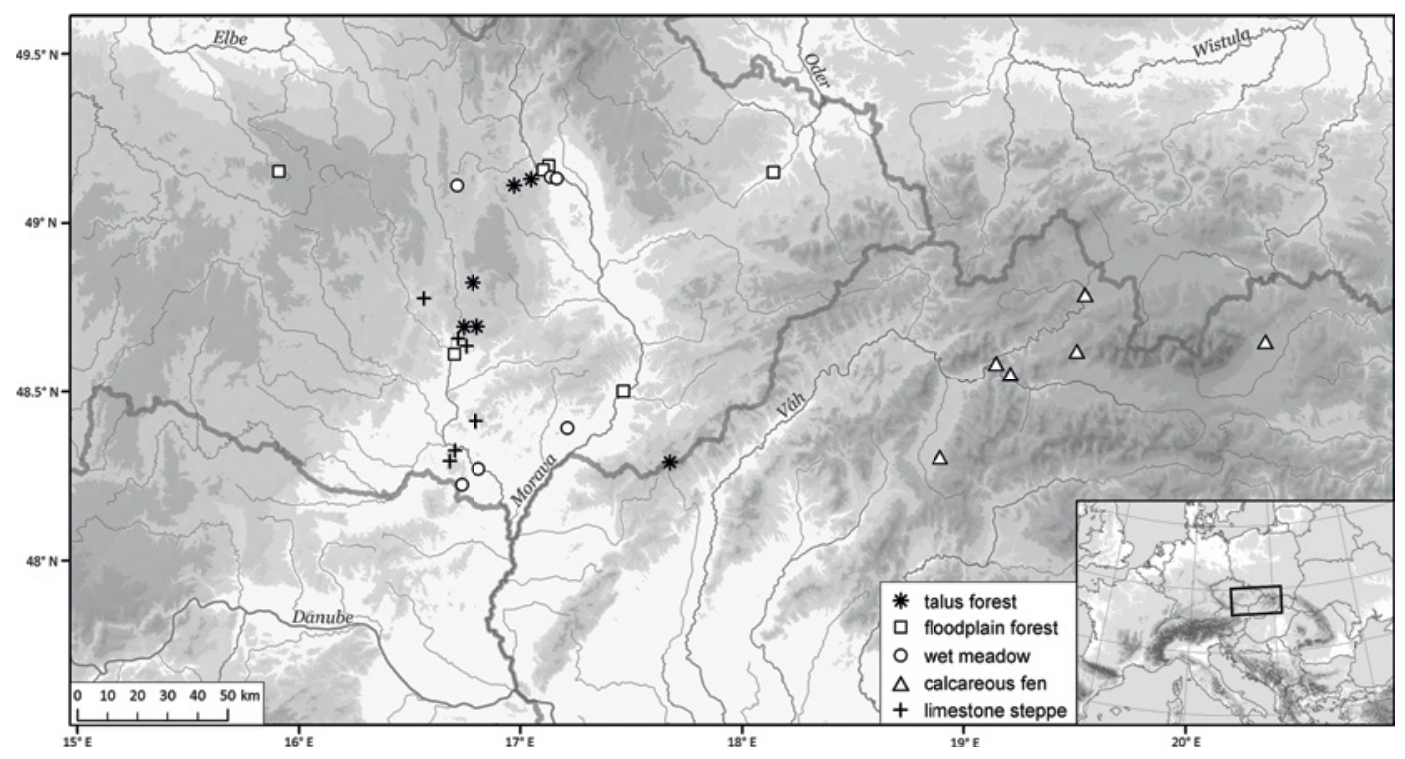

FIGURE 1 Location of 30 study sites categorised into five habitat types.

habitat types studied (i.e., talus forest, floodplain forest, wet meadow, calcareous fen, and limestone steppe). At each site, an approx. 10-litre sample of leaf litter and the upper soil layer was collected from a representative plot of $20 \times 20 \mathrm{~m}$. Additionally, the other 18 limestone steppe sites within the same area were sampled specifically for the steppe snail Granaria frumentum populations (see below). Predation by carabid beetles was observed at each of them, but there was no predation by the parasitoid fly Pherbellia limbata observed at three sites, indicating the absence of this predator. Therefore, these were excluded from the analyses related to this predator. Each sample was sieved in the field and then placed into a plastic bag. Samples were left to dry out in the laboratory and then processed by a standard protocol (Ložek, 1956). Snail shells were extracted from the processed samples using a soft forceps, determined to the species level under a dissection microscope based on Horsák et al. (2013b), and counted. All shells were examined for any sign of damage left by predators. Undamaged shells were crushed manually to search for the presence of predator exuviae within the shell or dry tissue of the snail body. Examined shells were then categorised as: (i) live individuals at the time of collection, (ii) undamaged empty shells, and (iii) empty shells showing any evidence of predation. The shells of the former type were excluded from the analyses as these represented snail individuals unaffected by predation. We were able to unambiguously recognise several types of unique evidence of predation including both external shell damage left by a predator or remains of the predator (exuviae) left within the shell (fig. 2). These include: (1) characteristic damage by gradual spiral biting that begins at the shell mouth and continues towards the apex of the shell, most likely caused by carabid beetles (Millar \& Waite, 2004); (2) the presence of Drilus beetle larval exuviae, which was found in the shell after breaking it manually (Schilthuizen et al., 1994; Baalbergen et al., 2016); (3) damage caused by gastropod predation represented by a specifically rasped hole in the shell wall with a typical gradual transition at 


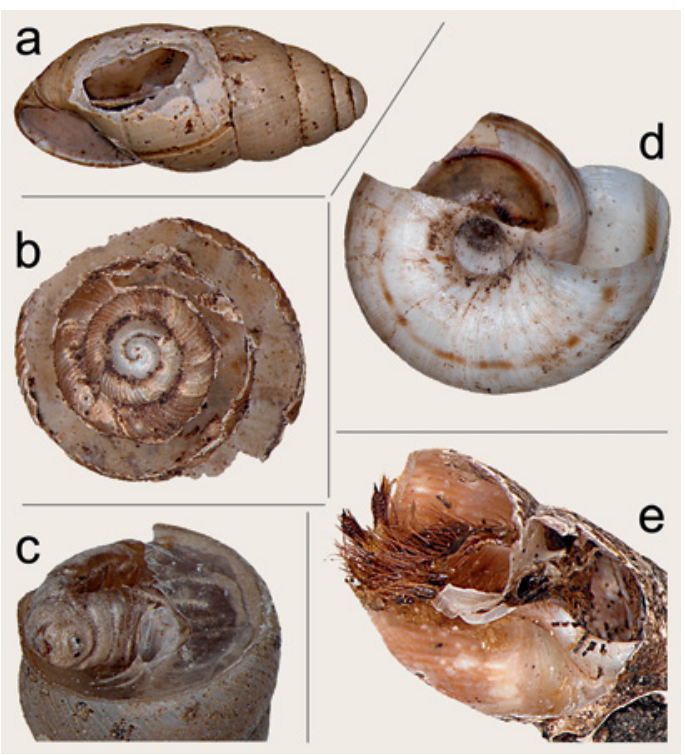

the edges of the opening; (4) a large part of shell sharply chipped off, usually from a side or spire, most likely by a bird; (5) the presence of the puparium of a predatory dipteran taxa hidden inside the shell; and (6) holes in the shell wall caused by unidentified predators, presumably by small mammals, classified as 'non-specific'.

\section{Data analyses}

We calculated the proportion of predated individuals for each site to analyse the relationship between predation rate and habitat types. It represented the number of all shells that clearly showed any of the predation types described above and divided by the all recorded empty shells in the sample. Differences in the predation rate among habitat types were tested using the $F$-statistic in the generalised linear regression model (GLM). Differences among individual predator intensities related to habitat types were tested using the KruskalWallis test. The Pearson correlation coefficient was used to test whether predation by snails is correlated with the occurrence of specific
FIGURE 2 Examples of the recorded evidence of predation caused by various predators. a) shell of Cochlicopa lubrica predated on by a snail; b) characteristic damage caused by a carabid beetle, here on a shell of Discus rotundatus; c) puparium of the parasitoid dipteran fly Pherbellia limbata within a Granaria frumentum shell (the shell was crushed manually); d) external damage to a Xerolenta obvia shell caused by bird predation; e) Drilus beetle larval exuviae within an Alinda biplicata shell (the shell was crushed manually). predatory snail species. To visualise changes in predation type composition among habitat types, multidimensional scaling (MDS) on the Bray-Curtis dissimilarity matrix was performed to find the main directions of variability in predation types among the habitats.

Predator specific preferences for different G. frumentum life stages were tested using the pairwise Wilcoxon test. Because a clear preference for different life stages of $G$. frumentum was detected for individual predators, i.e., chiefly carabid beetles and the parasitoid fly $P$. limbata, we analysed the predation rate separately for non-adult and adult shells (i.e., with fully developed mouth barriers; fig. 3a). The relationship between the predation rate on G. frumentum and its population densities was modelled using a linear regression model $(\mathrm{lm})$ with significance tested by the $F$-statistic. Counts were transformed using the natural logarithm (ln) to normalise their distribution. All analyses and graphics were performed in $\mathrm{R}$ program, version 3.4.4 (www.r-project. org). 


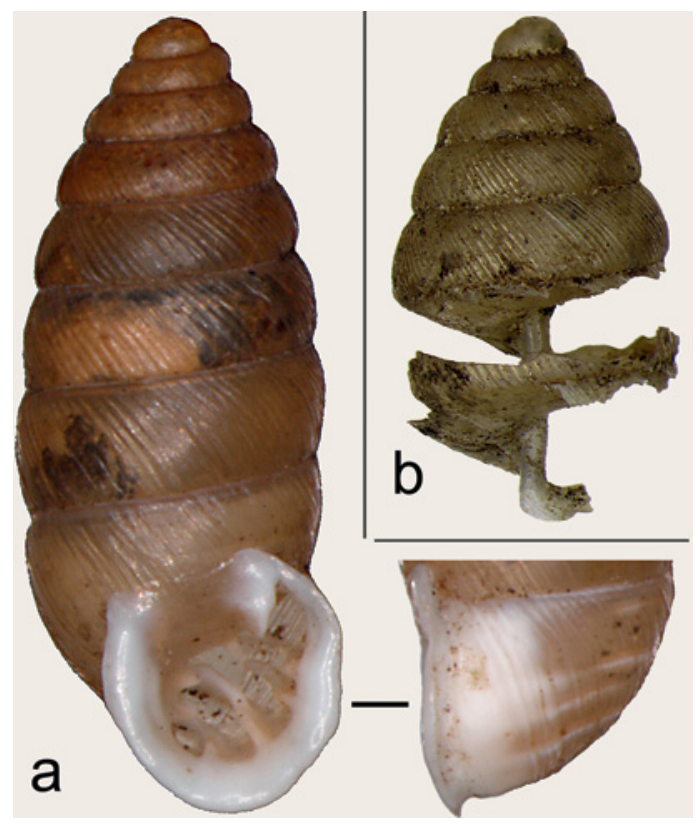

FIGURE 3 Shells of the steppe snail Granaria frumentum, a species with a thickened mouth lip in adults: a) shell of an adult individual from the front and lateral view; b) non-adult shell damaged by a carabid beetle as a result of predation.

\section{Results}

\section{Predation in relation to various habitats}

In total, there were 11,242 empty shells represented by 90 land snail species recorded at 30 study sites of five different habitat types. The number of empty shells per site varied from 84 to 1,877 (table 1). The highest numbers of empty shells were recorded in limestone steppes (688 shells on average) and the lowest in floodplain forests (201 shells on average). Out of all empty shells, 1,038 showed clear signs of external traces of predation or the predator's remains left within the shells. The total numbers of shells collected for each habitat type, along with the numbers of shells showing particular predation types are given in table 1 .

The minimal rate of predation per site ranged between o and $21 \%$ ( $8 \%$ on average). Using a generalised linear model, a significant difference in the minimal rate of predation was found among the habitat types (fig. 4). The highest values of minimal predation rate, significantly differing from all the other habitat types, were recorded at the steppe sites, showing on average $16 \%$ of shells with any traces of predation. Floodplain forest sites were, except for limestone steppe sites, also significantly different from calcareous fens, i.e., the habitat type showing the lowest minimal rate of predation. There were no differences between the predation rate detected in wet meadows, talus forests, and calcareous fens, which all showed the low rates of predation.

Beetles were found to be the most common predators of terrestrial snails in our samples. Shells indicating predation by beetles in proportion to all collected shells ranged from o to $15 \%$ ( $5 \%$ on average), and this type of predator was recorded at all study sites (except in one calcareous fen). With the exception of calcareous fens, about $55 \%$ to $76 \%$ of all predation events were addressed exactly to carabid beetle predation (fig. 5). However, predation by carnivorous snails was more common in calcareous fens, occurring at five 


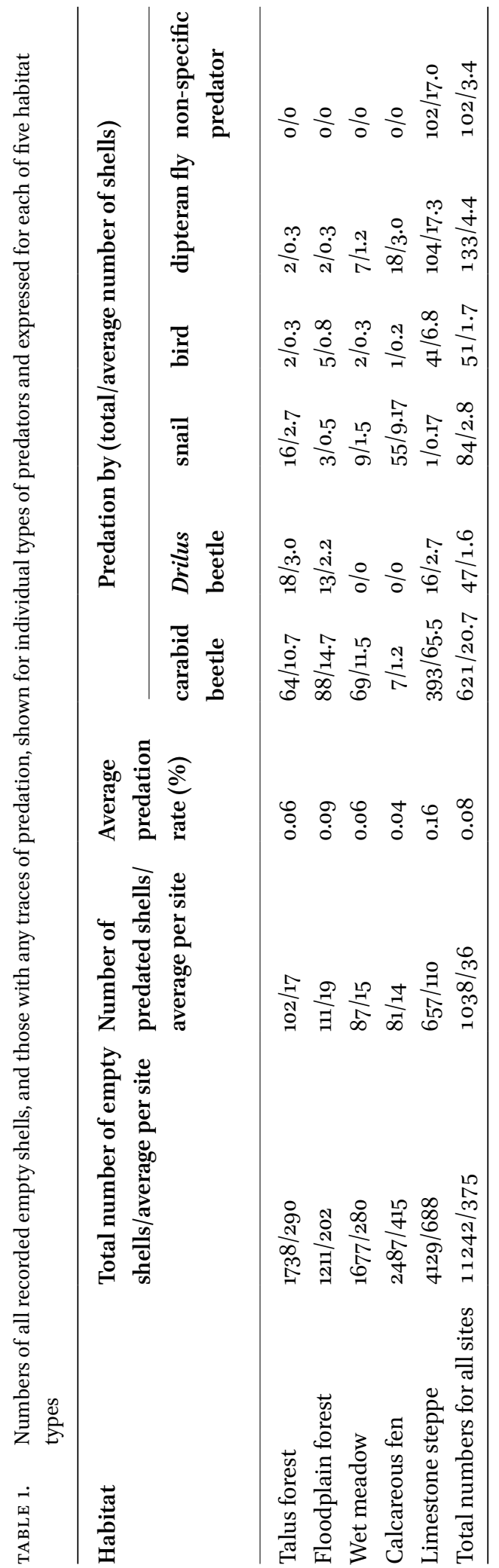




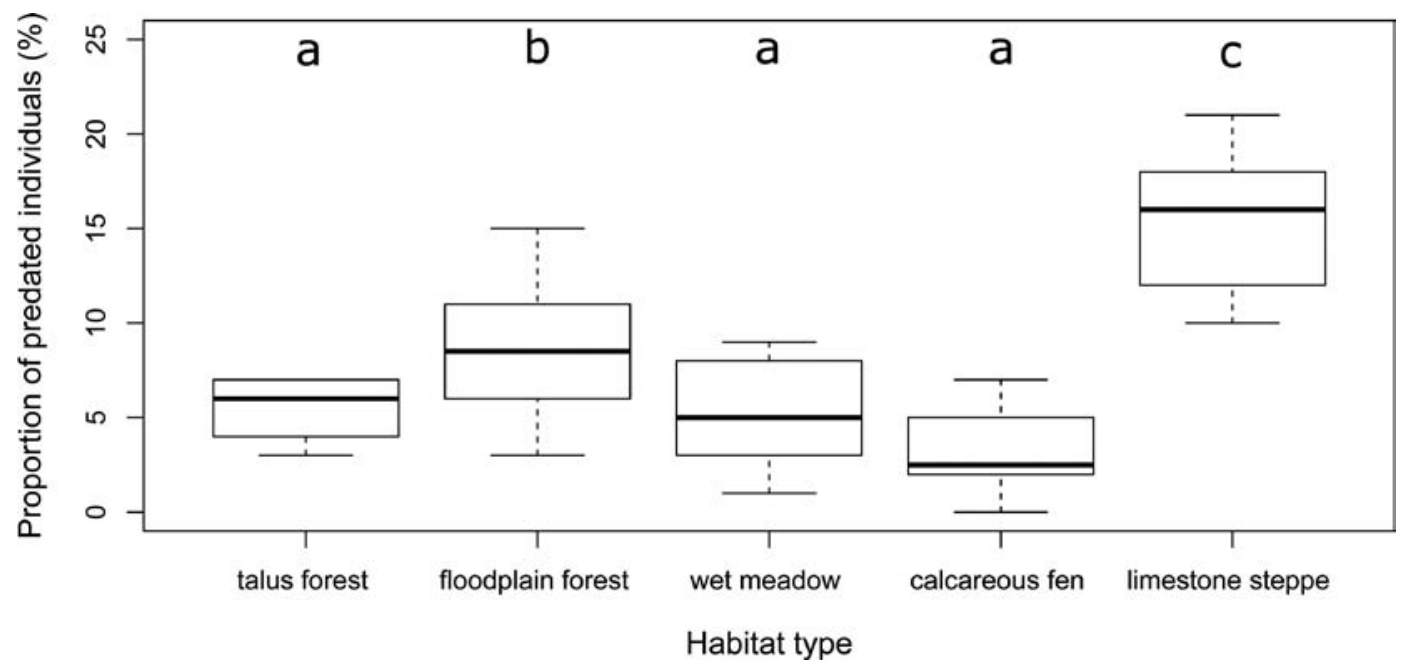

FIGURE 4 Variation in the minimal rate of predation recorded in six samples collected in each of five habitat types. Different letters refer to significant differences $(\mathrm{p}<0.05)$ among habitat types, based on a generalised linear model. The central line of each box refers to the median value, box height to the interquartile range, whiskers to the non-outlier range (i.e., 1.5 times the interquartile range at each side), and small circles to outliers.

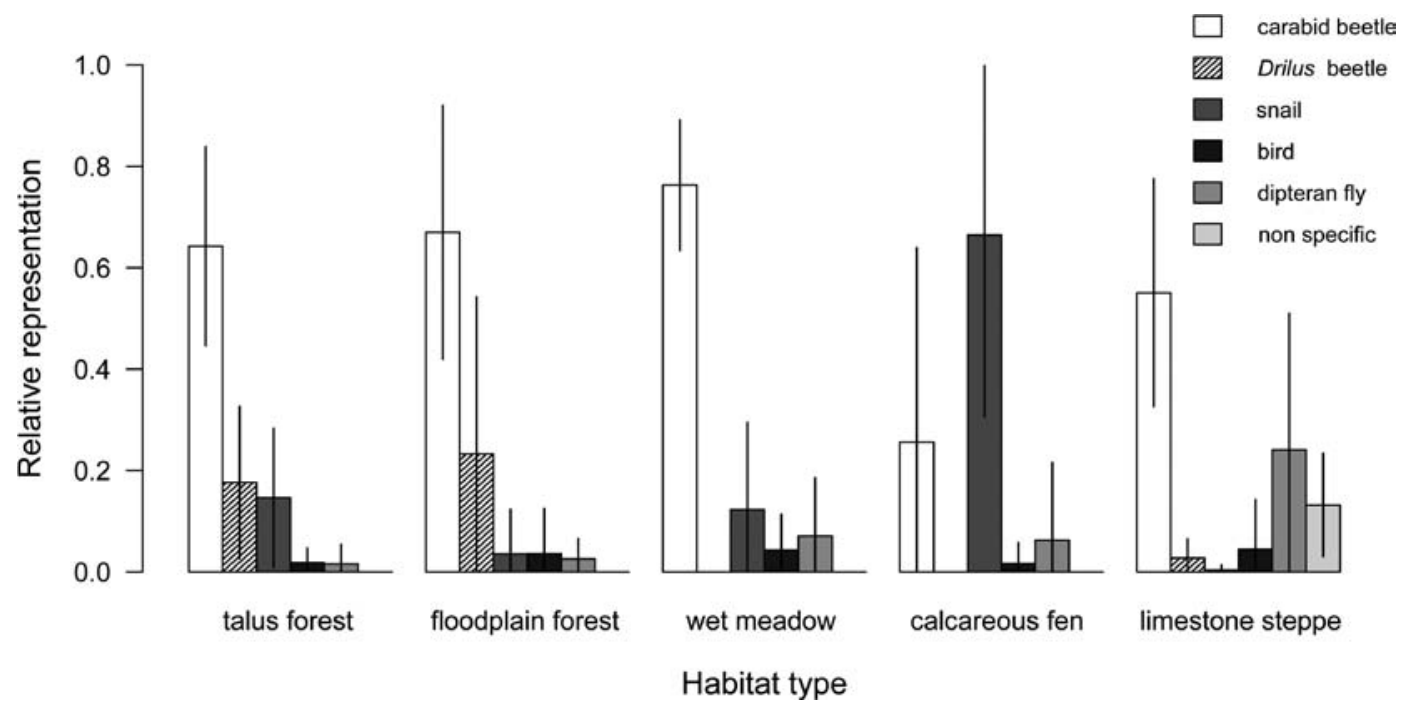

FIGURE 5 Relative representation of individual predation types recognised in six samples collected at each of five habitat types. The height of the column represents the average value, while the lines indicate the standard deviation. 
out of six studied sites and causing on average $65 \%$ of all predation events in the fens. Predation by some vertebrates and dipteran flies was observed at a low rate as well. Thereafter, we tested pairwise comparisons of the most common predators (carabid beetles and snails) among individual habitat types. Although, carabid beetle predation was clearly lowest at fen sites in contrast to the remaining habitat types, there were no significant differences found (Kruskal-Wallis test, p > 0.06). In contrast, predation intensity by snails was the highest in calcareous fens and significantly differed from all the other habitat types (Kruskal-Wallis test, $\mathrm{p}<0.05$ ).

By using proportional representation of individual predation types as variables in the multivariate analysis, the main change in the predation scheme was significantly shaped by differences in carabid beetle and snail predation rates ( $\mathrm{p}<$ 0.001, in 1999 permutations). Furthermore, differences in the dipteran fly predation rate significantly loaded onto the second ordination axis $(p=0.019)$. In the ordination diagram, a cluster of calcareous fens was found to express a unique nature, mainly due to the low rate of predation by carabid beetles (fig. 6). Likewise, limestone steppes did not overlap with the other sites, as they were characterised by a high rate of carabid predation and a null rate of snail predation. In contrast, talus forests and wet meadows almost entirely overlapped, and they also partially overlapped with floodplain forest sites.

\section{Predation in relation to Granaria frumentum life stages and population densities}

At 24 limestone steppe sites, 6,466 juvenile and 3,178 adult empty shells were collected, among which 1,571 shells showed any kinds of predation evidence (table 2). Predation on juveniles occurred in 918 cases caused by four different types of predators, and in 653 cases on adults, represented by three different predator types.

Carabid beetles were highly dominating among all the other predator types in nonadult stages, causing on average $82 \%$ of all predatory evidences (fig. 7). On the contrary,

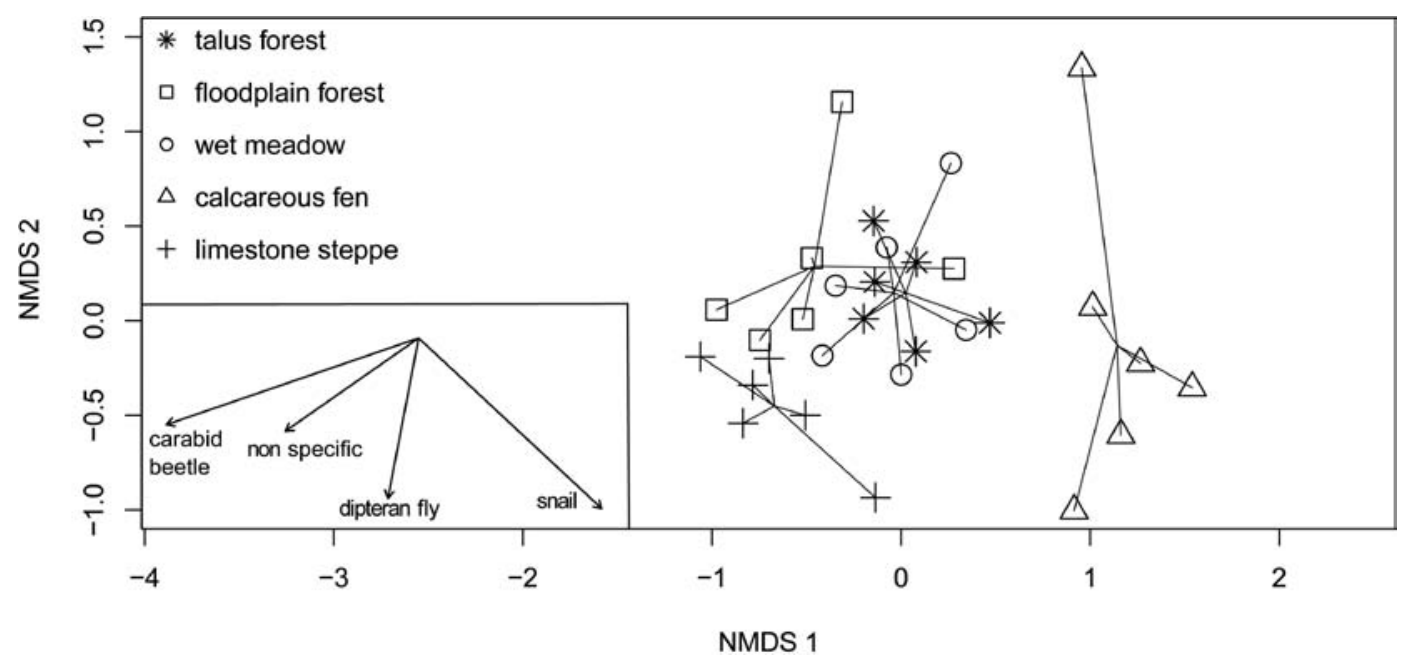

FIGURE 6 Non-metric multidimensional scaling (NMDS) of predation type composition at five study habitat types based on the Bray-Curtis distance. Parameters with a significant relationship to the first two ordination axes are shown in the bottom left corner. 
TABLE 2 Numbers of recorded juvenile and adult shells of Granaria frumentum and counts of shells with traces of predation recorded

\begin{tabular}{|c|c|c|c|}
\hline & & Juvenile & Adult \\
\hline \multirow{3}{*}{\multicolumn{2}{|c|}{$\begin{array}{l}\text { Number of empty shells/average per site } \\
\text { Number of predated shells/average per site } \\
\text { Average predation rate }(\%)\end{array}$}} & $6466 / 269$ & $3178 / 132$ \\
\hline & & $918 / 38$ & $653 / 27$ \\
\hline & & 0.10 & 0.18 \\
\hline & carabid beetle & $776 / 32.3$ & $9 / 0.4$ \\
\hline \multirow{3}{*}{$\begin{array}{l}\text { Predation by } \\
\text { (total/average } \\
\text { number of } \\
\text { shells) }\end{array}$} & $\begin{array}{l}\text { Drilus beetle } \\
\text { dipteran fly }\end{array}$ & $17 / 0.7$ & $189 / 7 \cdot 9$ \\
\hline & & $10 / 0.4$ & $455 / 19.0$ \\
\hline & non-specific predator & $11 / 4.8$ & o/o.o \\
\hline
\end{tabular}

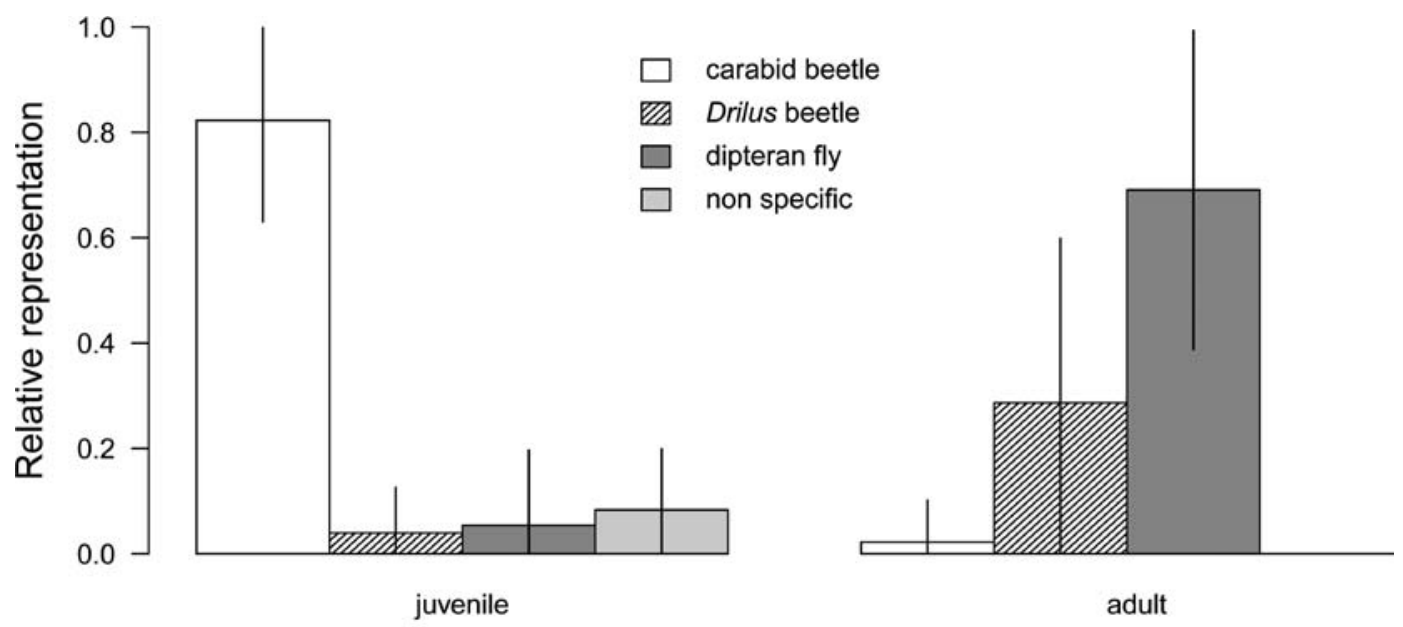

Life stage

FIGURE 7 Relative representation of individual predation types recognised in 24 populations of the snail Granaria frumentum from limestone steppe sites. Predation was considered separately for non-adult and adult shells. The height of the column represents the average value, while the lines indicate the standard deviation.

adults were successfully attacked by carabid beetles only in nine cases recorded at two sites. A clearly different pattern was found for adult shells, showing on average $69 \%$ and $29 \%$ of all predatory events caused by dipteran flies and Drilus beetle larvae, respectively.
All dipteran fly remains found within $G$. frumentum shells were identified as the puparia of the sciomyzid fly Pherbellia limbata, a highly specialised parasitoid. We confirmed significant (Wilcoxon test, $\mathrm{p}<0.001$ ) predator specific preference for different $G$. frumentum 
life stages as carabid beetles more frequently preyed on non-adult snails in contrast to adults that were significantly more predated on by P. limbata and Drilus beetle larvae.

These differences were related to the frequency of non-adult and adult shells recorded at each site. A significant linear relationship was observed between the number of nonadult and both absolute $\left(\operatorname{lm}_{22,24} ; \mathrm{F}=92.08\right.$; adj $\left.R^{2}=63.2 \% ; \mathrm{p}<0.001\right)$ and relative $\left(\operatorname{lm}_{22,24}\right.$; $\mathrm{F}=6.17$; adj $\left.\mathrm{R}^{2}=42.8 \% ; \mathrm{p}=0.021\right)$ values of predatory events by carabid beetles (fig. 8a,b). Likewise, the relation between the frequency of adults and the rate of predation by dipteran flies was tested. There was no relation between the $P$. limbata predation rate and numbers of adult $G$. frumentum $\left(\operatorname{lm}_{19,21} ; \mathrm{p}=\right.$ o.703). Predation was observed to be constant (fig. 8c), varying independently of population densities of the prey which turned out to be a linearly negative relationship $\left(\operatorname{lm}_{19,21} ; \mathrm{F}=8.96\right.$; adj $R^{2}=53.3 \% ; p=0.007$ ) for relative values (fig. 8d).

\section{Discussion}

There is strong evidence for a leading role of bottom-up regulation in land snail assemblages, which are controlled by a few abiotic factors such as calcium content, soil moisture, macroclimate, altitudinal gradient, and habitat continuity (Wäreborn, 1969; Cameron et al., 1980; Martin \& Sommer, 2004; Juřičková et al., 2008; Hettenbergerová et al., 2013; Albano et al., 2014; Nicolai \& Ansart, 2017). Conversely, the effect of top-down regulation representing predation and competition is only poorly understood. Most studies focusing on land snail communities and their predators have been restricted only to the effect of predation on particular land snail species, providing clear evidence of its significant effect on the studied snail species (e.g., Yom-Tov, 1970;
Schilthuizen et al., 1994; Sugiura et al., 2006; Meyer \& Shiels, 2009; Rosin et al., 2011). There have been virtually no studies evaluating predation pressure on entire snail assemblages, but see Millar \& Waite (2004). In general, the overall predation rate was found to be rather low and more or less equally distributed across various land snail species within the assemblage. This means that predation seems not to have any strong effect on individual snail population dynamics.

\section{Predation rate and differences among habitats}

Considering the number of various specific malacophagous predators of land snails, we can assume the rate of predation on snails to be rather high. These predators include mainly beetles (Konuma et al., 2011), dipteran flies (Knutson \& Vala, 2011), carnivorous gastropods (Barker \& Efford, 2004), harvestmen (Nyffeler \& Symondson, 2001), birds and mammals (Rosin et al., 2011). Our results confirm this prediction as we found on average $8 \%$ of snail individual being predated on, with a maximum value of $21 \%$. These counts, however, are very likely underestimates and should be considered as the minimal rate of realized predation. Such a bias is related to the limits of the method applied, because it does not allow us to record predation on snail eggs (e.g., Baur \& Baur, 1990; Hatteland et al., 2010) and slugs (Pakarinen, 1994; Bohan et al., 2000). Most importantly, it cannot capture predation events in which the predator enters the snail through the aperture with no evidence (e.g., damage to the shell, exuviae inside the shell) left to indicate predation (Nyffeler \& Symondson, 2001; Sugiura et al., 2006). It is also assumed that damaged shells can break into unidentifiable fragments and dissolve more easily than intact shells, which can also add to the underestimation of the predation rate. However, even damaged shells can 


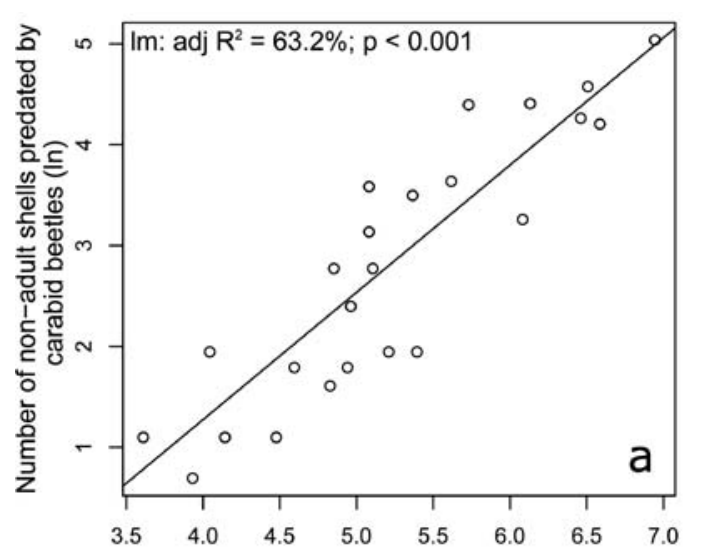

Number of non-adult shells recorded (In)

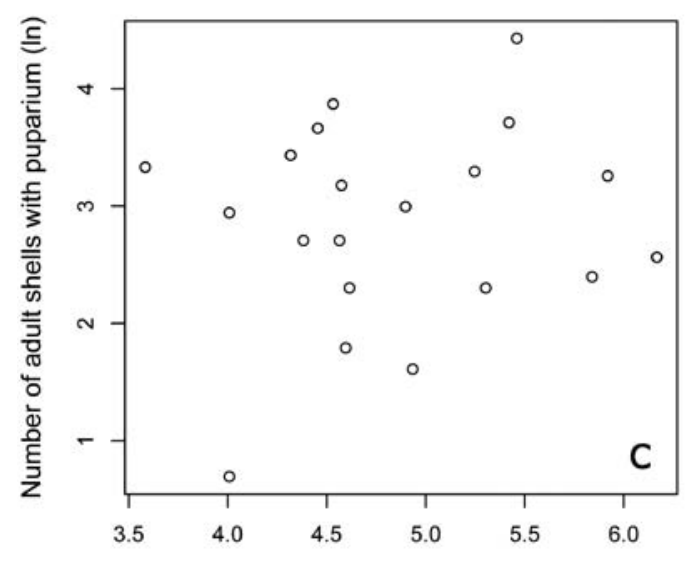

Number of adult shells recorded (In)

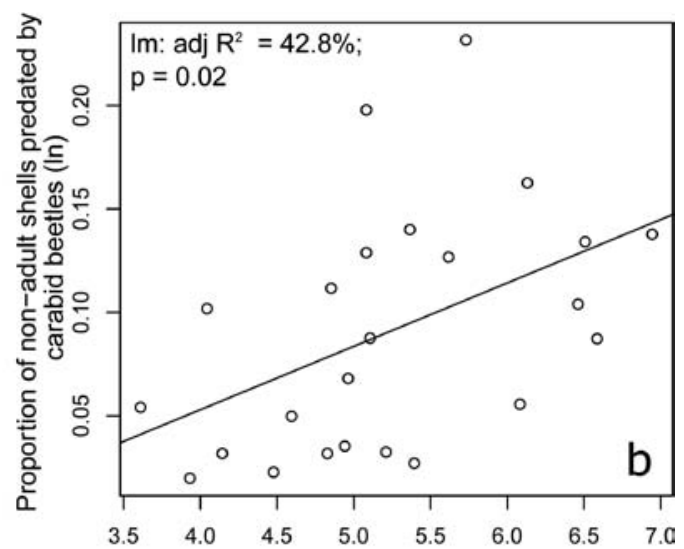

Number of non-adult shells recorded (In)

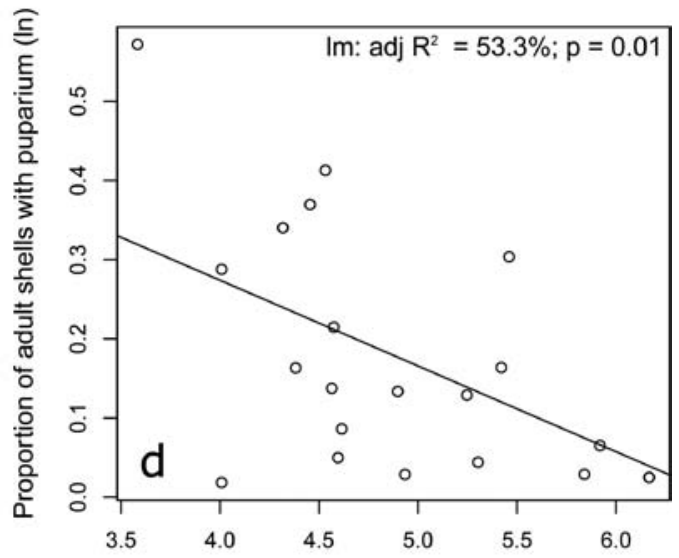

Number of adult shells recorded (In)

FIGURE 8 Relationship between the number of shells predated on by carabid beetles $(a, b)$ or the parasitoid Pherbellia limbata (c, d) and absolute (a, c) or relative numbers $(b, d)$ of recorded empty shells of Granaria frumentum fitted by linear regression (lm).

persist in the environment for a relatively long time (Pearce, 2008).

Because there are virtually unlimited food resources for the majority of snail species, as they mostly feed on decaying plant matter, their interspecific competition is typically considered negligible (e.g., Waldén, 1981; but see Horsák et al., 2014 for a review). However, there are clear examples of biotic interactions among closely related or similar-sized species, usually in rather stressed environments with limited fauna (Cameron \& Carter, 1979; Mordan, 1977; Baur \& Baur, 1990; Cameron et al., 2003). If food resources are not limited and there is only a negligible effect of interspecific predation, top-down regulation by malacophagous predators seems likely to be the main mechanism controlling snail population densities. Our results also showed that predation caused by carnivorous gastropods is indeed 
negligible, except for calcareous fen assemblages. However, in all habitat types, interspecific and intraspecific predation on eggs could not be detected by our empty shell analysis, although it is known that egg predation and even egg cannibalism can act as an important regulating factor in snail populations (Baur, 1988).

The highest minimal rate of predation was observed at limestone steppe sites compared to the other habitat types. Steppe sites were characterised by the dominance of two species: Xerolenta obvia (Menke, 1828) and Granaria frumentum. Thus, a possible explanation for the higher predation rate seems to be the high availability and abundance of these species, representing favourable food sources. Besides, during dry periods when there are probably few alternative prey types, estivating snails seem to be easy prey. In addition to food, snails may also offer a certain amount of water to improve the predator's water balance (Shkolnik \& Borut, 1969). Indeed, in agreement with our predictions, we obtained statistically significant support for linearly increasing predation of carabid beetles on G. frumentum population densities, showing a positive correlation. It is generally assumed that there will be more malacophagous beetles in places with a high abundance of terrestrial gastropods, and hence the intensity of beetle predation will be also high. A polyphagous feeding strategy apparently allows carabids to switch between different food sources at times when gastropod densities decline and go back to snail prey when their populations have recovered (Symondson et al., 2002).

\section{The main predators and their preferences}

Most recorded cases of predation were associated with carabid beetles, which were the most likely predators causing shell damage of that pattern (Millar \& Waite, 2004). Harvestmen of the genus Ischyropsalis are other possible predators known to be capable of breaking snail shells in a similar way as carabids (Martens, 1965). Millar \& Waite (2004) speculated that harvestmen break out larger parts of the shell and with a less regular pattern than carabid beetles. However, we can exclude possibility of this predation as the harvestmen prefers habitats with much higher elevation than those of our sites (Martens, 1965).

The strategy associated with morphological adaptations of individual carabid beetles to breaking the shell in the given way is called procerisation (after the genus Procerus). Another attack strategy often used by carabid beetles is called cychrisation (after the genus Cychrus). It is used by carabids characterised by elongated mandibles, which allow them to reach the retracted snail body within the shell by entering the shell through the aperture (Thiele, 1977). Again, empty shell analysis does not allow us to record this type of predation. Likewise, some other beetle predators using the same type of predation strategy as Cychrus species, for example the Lampyridae family (Wang et al., 2007), are also invisible using this method. Drilus beetle larvae represent anotherwell-known malacophagous predator entering the shell through the aperture area. However, unlike other beetles that attack the snail through the aperture, these beetles always leave an exuviae within the shell before leaving the prey (Baalbergen et al., 2014). Exuviae may serve as clear evidence of this type of predation when found after breaking the shell in the laboratory (Millar \& Waite, 2004; Baalbergen et al., 2016).

Although carabid beetle predation was clearly the lowest at fen sites, in contrast to the remaining habitat types, there were no significant differences found. However, there was clear evidence that carabid beetle predation was rare in fens, so a significant difference could be reached when the highest value 
of carabid beetle predation at fen sites was excluded (Kruskal-Wallis test, $\mathrm{p}<\mathrm{0.01}$ ). The low rate of carabid predation could be related with the humid environment and also with the mostly very small size of gastropods occurring in fens (Schamp et al., 2010), which do not represent a suitable prey type for most carabids. In contrast, fen samples were characterised by a statistically higher representation of gastropod predation, possibly indicating the high importance of intraspecific competition among snails in this environment. This is in line with Horsák et al. (2014), as they found indirect evidence suggesting intraspecific competition at small spatial scales. This is likely related to the fact that calcareous fens sites typically have high snail abundances (Cernohorsky et al., 2010) which make snailsnail interactions more likely. Further, the dominance of mosses and Cyperaceae plants reduces the amount of favourable food sources, as snails prefer dicotyledons as a more palatable food source (Grime et al., 1968). The predation rate by snails at the studied fen sites correlated with the abundance of snail species of the families Zonitidae and Oxychilidae $(\mathrm{r}=0.76, \mathrm{p}=0.024)$, which are known for their facultative malacophagy (Mordan, 1977; Badie \& Rondelaud, 1985; Myzyk, 2014).

We also found evidence for predation by birds at all habitats, but only to a small extent. Birds are known to carry snails away to a specific location (an anvil) at which they break their shells using solid objects, such as stones (Morris, 1954; Goodhart, 1958), and then feed on snail tissues. Therefore, damaged shells can accumulate at such places, which might underestimate or overestimate the rate of bird predation at plots without or with an anvil, respectively. Further, birds are also known to swallow the entire snail along with its shell (Wada et al., 2012), which also underestimates their predation rate when assessed based on empty shell analysis. Last but not least, dipterans were another type of predator recognised in our samples. Because most dipteran species found are classified as necrophagous (Smith, 1989; Papp \& Darvas, 200o), these likely did not contribute to predation. We also recorded several species known as parasitoids, however these were all very rare, but Pherbellia limbata feeding on $G$. frumentum.

\section{Predator preferences, shell defence and predation on Granaria frumentum}

Gastropods are assumed to be vulnerable to predation as they are not toxic and mostly also not unpalatable or inedible. Apart from sticky mucus production, the presence of the shell represents the main gastropod defence. Vermeij (1982) showed that unsuccessful predation, which is a necessary condition for the evolution of anti-predatory characteristics, is the rule for the vast majority of interactions between predators and their prey. Passive protection in a thick, coiled shell is the dominant pattern in the coevolutionary response of gastropods to predators. Shell morphological traits (e.g., size, shape, thickness, sculpture) are accordingly interpretable as antipredator adaptations (Vermeij, 1987, 1993). Although much of this work was conducted on aquatic and sea littoral gastropods, all these findings about passive shell protection may be valid for terrestrial gastropods as well. Some species possess a thick reinforced aperture area, which is supposed to serve as a defensive barrier against predators, i.e., those breaking the shell from the aperture. Various aperture modifications have been found to have an important effect on reducing water loss (Machin, 1967). Denticles and other structures developed in the aperture area are considered to have an anti-predation function (Solem, 1972; Gittenberger, 1995; Liew \& Schilthuizen, 2014). While there have been studies focusing on the advantages of overall shell thickness in 
relation to predation (Yom-Tov, 1970; Quensen \& Woodruff, 1997), the importance of a thickened aperture itself has never been analysed in more detail.

Our data show that a thickened aperture area of the shell has an important antipredation function against predators that break the shell from the aperture. We observed clear preferences of different predators for juvenile and adult stages of the studied snail G. frumentum, a snail characterised by a strong mouth barrier in fully developed shells. Only nine out of 785 analysed adult shells showed damage caused by a carabid beetle. In contrast, juvenile shells with a soft edge of the aperture showed a higher percentage of predation by carabid beetles because it is apparently easier to break their shells. However, a significantly higher number of adult snails was predated on by the sciomyzid fly $P$. limbata and Drilus beetle larvae in contrast to juveniles. This is likely due to the presence of a suitable amount of food and space provided by adult snails for these predators. We can also hypothesise that a predator hidden within an adult individual is highly unlikely to become the prey of a carabid beetle as they very rarely succeed in feeding on adult snails. The function of a thickened shell mouth margin as an effective protection against predators breaking shells from the aperture was also confirmed by our observations on door snails (Clausiliidae). These snails also possess a reinforced aperture associated with their maturity. All 75 door snail individuals predated on by carabid beetles were non-adults, i.e., without a thickened mouth margin. In contrast, the size of the prey in relation to the size of the predator rather than its life stage seems to be more relevant for predators hunting snail species that do not undergo any aperture modifications during their lifespan.

Unlike the evidence for linearly increasing predation by carabid beetles at sites with a high abundance of prey, no pattern for the predation by $P$. limbata on $G$. frumentum was found as the probability of parasitism in the samples did not increase with host density. There is evidence for density-related parasitism in insect host-parasitoid systems (e.g., Lessells, 1985; Reeve \& Murdoch, 1985). However, each host-parasitoid system has its own specificity (Stiling, 1987). Contrary to polyphagous carabid beetles, the parasitoid fly P. Limabata is a highly specialised predator preying strictly on G. frumentum (NerudováHorsáková et al., 2016) and is unable to switch between hosts in response to population size fluctuations. Therefore, it is likely that the parasitoid population size reflects the mean population density of the host. Another possible explanation for a constant density of this fly can be related to competition with other malacophagous predators, for example Drilus beetles, which were also found feeding on $G$. frumentum in our samples. This might also contribute to the regulation of the size of the parasitoid population at a certain level.

\section{Conclusions}

This study provides the first comprehensive evidence that land snail assemblages can face numerous attacks by predators of various taxonomic groups. The proportion of predated individuals can, however, notably vary depending on the habitat type. As both internal and external damage left by predators on the shells of their victims are easy to recognise and identify, the analysis of empty shell assemblages is a powerful method by which to study predation pressure on snail populations. However, we stress that predation invisible to this method (e.g., consumption of the entire snail individual) represents the main source of a possible bias and further studies are needed to estimate this. 
We documented clear predation specialisation for different life stages of the snail prey as an effective strategy for how to cope with specific defensive structures in the shell mouth. However, the same barriers can provide important advantage for predators that manage to hide in adult shells so they are not eaten by other snail predators. The existence of mouth barriers seems to act as both an advantage and a disadvantage, and deserves further investigation as an interesting evolution mechanism of predator-prey coevolution. The common existence of shell mouth barriers suggests that their evolutionary success may be related to a higher probability of predation caused by nonspecific predators breaking the victim's shell from its mouth than by rare and highly specific predators developing inside the shell.

\section{Acknowledgements}

We are grateful to P. Albano and M. Schilthuizen for useful comments on an earlier version of the manuscript. This study was supported by the institutional support of Masaryk University and by the Czech Science Foundation ( $\mathrm{P}_{504-19-01775 S}$ ).

\section{References}

Albano, P.G., D'occhio, P., Strazzari, G., Succetti, F. \& Sabelli, B. (2014) Land-mollusc forest communities along an altitudinal transect in northern Italy.J. Molluscan Stud., 80, 55-61.

Ansart, A., Vernon, P. \& Daguzan, J. (2001) Photoperiod is the main cue that triggers supercooling ability in the land snail, Helix aspersa (Gastropoda: Helicidae). Cryobiology, 42, 266-273.

Baalbergen, E., Helwerda, R., Schelfhorst, R., Caja, R.F.C., van Moorsel, C.H., Kundrata, R., Francisco, W.W., Giokas, S. \& Schilthuizen, M. (2014) Predator-preyinteractions between shell-boring beetle larvae and rock-dwelling land snails. PLOS ONE, 9, e100366.

Baalbergen, E., Schelfhorst, R. \& Schilthuizen, M. (2016) Drilus larvae in the Netherlands (Coleoptera: Elateridae: Drilini). Entomolog. Ber., 76, 165-173.

Badie, A. \& Rondelaud, D. (1985) Experimental studies on the predation of Cionella lubrica Mueller by Nesovitrea hammonis Stroem. Ann. Rech. Vet., 16, 105-109.

Barker, G.M. (2004) Natural Enemies of Terrestrial Molluscs. CABI Publishing.

Barker, G.M. \& Efford, M.G. (2004) Predatory gastropods as natural enemies of terrestrial gastropods and other invertebrates. In: G.M. Barker (Ed.) Natural Enemies of Terrestrial Molluscs, pp. 279-403. CABI.

Baur, B. (1988) Population regulation in the land snail Arianta arbustorum: density effects on adult size, clutch size and incidence of egg cannibalism. Oecologia, 77, 390-394.

Baur, B. (1992) Cannibalism in Gastropods. Oxford University Press.

Baur, B. \& Baur, A. (1990) Experimental evidence for intra-and interspecific competition in two species of rock-dwelling land snails. J. Anim. Ecol., 59, 301-315.

Bohan, D.A., Bohan, A.C., Glen, D.M., Symondson, W.O., Wiltshire, C.W. \& Hughes, L. (2000) Spatial dynamics of predation by carabid beetles on slugs. J. Anim. Ecol., 69, 367-379.

Cameron, R.A.D. \& Carter, M.A. (1979) Intra-and interspecific effects of population density on growth and activity in some helicid land snails (Gastropoda: Pulmonata). J. Anim. Ecol., 48, 237-246.

Cameron, R.A.D., Carter, M.A. \& Palles-Clark, M.A. (1980) Cepaea on Salisbury Plain: patterns of variation, landscape history and habitat stability. Biol. J. Linn. Soc. Lond., 14, 335-358.

Cameron, R.A.D., Mylonas, M., Triantis, K., Parmakelis, A. \& Vardinoyannis, K. (2003) Landsnail diversity in a square kilometre of Cretan maquis: modest species richness, high density 
and local homogeneity. J. Molluscan Stud., 69, 93-99.

Cernohorsky, N.H., Horsák, M. \& Cameron, R.A.D. (2010) Land snail species richness and abundance at small scales: the effects of distinguishing between live individuals and empty shells. J. Conchol., 40, 233-241.

Chiba, S. (2007) Morphological and ecological shifts in a land snail caused by the impacts of an introduced predator. Ecol. Res., 22, 884-891.

Eskelson, M.J., Chapman, E.G., Archbold, D.D., Obrycki, J.J. \& Harwood, J.D. (2011) Molecular identification of predation by carabid beetles on exotic and native slugs in a strawberry agroecosystem. Biol. Control, 56, 245-253.

Fournie, J. \& Chetail, M. (1984) Calcium dynamics in land gastropods. Am. Zool., 24, 857-870.

Gittenberger, E. (1995) Adaptations of the aperture in terrestrial gastropod-pulmonate shells. Neth. J. Zool., 46, 191-205.

Goodhart, C.B. (1958) Thrush predation on the snail Cepaea hortensis. J. Anim. Ecol., 27, 47-57.

Graveland, J. \& Gijzen, T.V. (1994) Arthropods and seeds are not sufficient as calcium sources for shell formation and skeletal growth in passerines. Ardea, 82, 299-314.

Griffiths, O., Cook, A. \& Wells, S.M. (1993) The diet of the introduced carnivorous snail Euglandina rosea in Mauritius and its implications for threatened island gastropod faunas. J. Zool., 229, 79-89.

Grime, J.P., MacPherson-Stewart, S.F. \& Dearman, R.S. (1968) An investigation of leaf palatability using the snail Cepaea nemoralis L. J. Ecol., 56, 405-420.

Harper, G.L., King, R.A., Dodd, C.S., Harwood, J.D., Glen, D.M., Bruford, M.W. \& Symondson, W.O.C. (2005) Rapid screening of invertebrate predators for multiple prey DNA targets. Mol. Ecol., 14, 819-827.

Hatteland, B.A., Grutle, K., Mong, C.E., Skartveit, J., Symondson, W.O.C. \& Solhøy, T. (2010) Predation by beetles (Carabidae, Staphylinidae) on eggs and juveniles of the Iberian slug Arion lusitanicus in the laboratory. Bull. Entomol. Res., 100, 559-567.

Hettenbergerová, E., Horsák, M., Chandran, R., Hájek, M., Zelený, D. \& Dvořáková, J. (2013) Patterns of land snail assemblages along a finescale moisture gradient. Malacologia, 56, 31-42. Horsák, M., Chytrý, M., Hájková, P., Hájek, M., Danihelka, J., Horsáková, V., Nikolai, E., Dmitry, A.G., Kočí, M., Lustyk, P., Nekola, J.C., Preislerová, Z. \& Valachovič, M. (2015) European glacial relict snails and plants: environmental context of their modern refugial occurrence in southern Siberia. Boreas, 44, 638-657.

Horsák, M., Hájek, M., Spitale, D., Hájková, P., Dítě, D. \& Nekola, J.C. (2012) The age of island-like habitats impacts habitat specialist species richness. Ecology, 93, 1106-1114.

Horsák, M., Lososová, Z., Čejka, T., Juřičková, L. \& Chytrý, M. (2013a) Diversity and biotic homogenization of urban land-snail faunas in relation to habitat types and macroclimate in 32 central European cities. PIOS ONE, 8, e71783.

Horsák, M., Jư̌ičková, L. \& Picka, J. (2013b) Měkkýši České a Slovenské republiky. Molluscs of the Czech and Slovak Republics. Kabourek.

Horsák, M., Polášková, V., Zhai, M., Bojková, J., Syrovátka, V., Šorfová, V., Schenková, J., Polášek, M., Peterka, T. \& Hájek, M. (2018) Spring-fen habitat islands in a warming climate: partitioning the effects of mesoclimate air and water temperature on aquatic and terrestrial biota. Sci. Total Environ., 634, 355-365.

Horsák, M., Zelený, D. \& Hájek, M. (2014) Land snail richness and abundance along a sharp ecological gradient at two sampling scales: disentangling relationships. J. Molluscan Stud., 80, 256-264.

Hoso, M. \& Hori, M. (2006) Identification of molluscan prey from feces of Iwasaki's slug snake, Pareas iwasakii. Herpetol. Rev., 37, 174-176.

Hoso, M., Kameda, Y., Wu, S.P., Asami, T., Kato, M. \& Hori, M. (2010) A speciation gene for leftright reversal in snails results in anti-predator adaptation. Nat. Commun., 1, 133. 
Hylander, K., Nilsson, C., Jonsson, B.G. \& Göthner, T. (2005) Differences in habitat quality explain nestedness in a land snail meta-community. Oikos, 108, 351-361.

Juřičková, L., Horsák, M., Cameron, R., Hylander, K., Míkovcová, A., Hlaváč, J.Č. \& Rohovec, J. (2008) Land snail distribution patterns within a site: the role of different calcium sources. Eur. J. Soil Biol., 44, 172-179.

Kappes, H. (2006) Relations between forest management and slug assemblages (Gastropoda) of deciduous regrowth forests. For. Ecol. Manage., $237,450-457$.

Knutson, L.V. \& Vala, J.C. (2011) Biology of SnailKilling Sciomyzidae Flies. Cambridge University Press.

Konuma, J., Nagata, N. \& Sota, T. (2011) Factors determining the direction of ecological specialization in snail-feeding carabid beetles. Evolution, $65,408-418$.

Lessells, C.M. (1985) Parasitoid foraging: should parasitism be density dependent? J. Anim. Ecol., 54, 27-41.

Liew, T.S. \& Schilthuizen, M. (2014) Association between shell morphology of micro-land snails (genus Plectostoma) and their predator's predatory behaviour. PeerJ, 2, e329.

Ložek, V. (1956) Klič československých měkkýšũ. Vydavatel'stvo Slovenskej akadémie vied.

Machin, J. (1967) Structural adaptation for reducing water-loss in three species of terrestrial snail.J. Zool., 152, 55-65.

Martens, J. (1965) Verbreitung und Biologie des Schneckenkankers Ischyropsalis hellwigi. Nat. Mus., 95, 143-149.

Martin, K. \& Sommer, M. (2004) Relationships between land snail assemblage patterns and soil properties in temperate-humid forest ecosystems. J. Biogeogr., 31, 531-545.

Meyer, W.M. \& Shiels, A.B. (2009) Black rat (Rattus rattus) predation on nonindigenous snails in Hawai 'i: complex management implications. Pac. Sci., 63, 339-347.

Meyer, W.M. \& Yeung, N.W. (2011) Trophic relationships among terrestrial molluscs in a Hawaiian rain forest: analysis of carbon and nitrogen isotopes. J. Trop. Ecol., 27, 441-445.

Millar, A.J. \& Waite, S. (1999) Molluscs in coppice woodland. J. Conchol., 36, 25-48.

Millar, A.J. \& Waite, S. (2004) Patterns of shell damage among snails from a coppice woodland in Sussex, England. J. Conchol., 38, 421-440.

Mordan, P.B. (1977) Factors affecting the distribution and abundance of Aegopinella and Nesovitrea (Pulmonata: Zonitidae) at Monks Wood National Nature Reserve, Huntingdonshire. Biol.J. Linn. Soc. Lond., 9, 59-72.

Morris, D. (1954) The snail-eating behaviour of thrushes and blackbirds. Br. Birds, 47, 33-49.

Myzyk, S. (2014) The predator Aegopinella nitidula (Draparnaud, 1805) and its prey Perforatella bidentata (Gmelin, 1791)(Gastropoda: Pulmonata). Folia Malacol., 22, 225-227.

Nekola, J.C. (2003) Large-scale terrestrial gastropod community composition patterns in the Great Lakes region of North America. Divers. Distrib., 9, 55-71.

Nerudová-Horsáková, J., Murphy, W.L. \& Vala, J.C. (2016) Biology and immature stages of Pherbellia limbata (Diptera: Sciomyzidae), a parasitoid of the terrestrial snail Granaria frumentum. Zootaxa, 4117, 048-062.

Nicolai, A. \& Ansart, A. (2017) Conservation at a slow pace: terrestrial gastropods facing fastchanging climate. Conserv. Physiol., 5, oxo07.

Nyffeler, M. \& Symondson, W.O. (2001) Spiders and harvestmen as gastropod predators. Ecol. Entomol., 26, 617-628.

Ogren, R.E. \& Sheldon, J.K. (1991) Ecological observations on the land planarian Bipalium pennsylvanicum Ogren, with references to phenology, reproduction, growth rate and food niche. J. $\mathrm{Pa}$. Acad. Sci., 65, 3-9.

Pakarinen, E. (1994) The importance of mucus as a defence against carabid beetles by the slugs Arion fasciatus and Deroceras reticulatum. J. Molluscan Stud., 6o, 149-155.

Papp, L. \& Darvas, B. (200o) Contributions to a Manual of Palaearctic Diptera. 1: General and Applied Dipterology. Science Herald. 
Pearce, T.A. (2008) When a snail dies in the forest, how long will the shell persist? Effect of dissolution and micro-bioerosion. Am. Malacol. Bull., $26,111-118$.

Quensen, J.F. \& Woodruff, D.S. (1997) Associations between shell morphology and land crab predation in the land snail Cerion. Funct. Ecol., 11, 464-471.

Reeve, J.D. \& Murdoch, W.W. (1985) Aggregation by parasitoids in the successful control of the California red scale: a test of theory. J. Anim. Ecol., $55,797-816$.

Ř́ihová, D., Janovský, Z., Horsák, M. \& Jư̌ičková, L. (2018) Shell decomposition rates in relation to shell size and habitat conditions in contrasting types of Central European forests. J. Molluscan Stud., 84, 54-61.

Rosin, Z.M., Olborska, P., Surmacki, A. \& Tryjanowski, P. (2011) Differences in predatory pressure on terrestrial snails by birds and mammals. J. Biosci., 36, 691-699.

Schamp, B., Horsák, M. \& Hájek, M. (2010) Deterministic assembly of land snail communities according to species size and diet.J. Anim. Ecol., 79, 803-810.

Schilthuizen, M., Kemperman, T.C. \& Gittenberger, E. (1994) Parasites and predators in Albinaria (Gastropoda Pulmonata: Clausiliidae). Bios, 2, 177-186.

Shachak, M., Safriel, U.N. \& Hunum, R. (1981) An exceptional event of predation on desert snails by migratory thrushes in the Negev Desert, Israel. Ecology, 62, 1441-1449.

Shkolnik, A. \& Borut, A. (1969) Temperature and water relations in two species of spiny mice (Acomys).J. Mammal., 50, 245-255.

Smith, K.G.V. (1989) An Introduction to the Immature Stages of British Flies: Handbook for the Identification of British Insects, Part 14, Vol. 10. Royal Entomological Society of London.

Solem, A. (1972) Microarmature and barriers in the aperture of land snails. Veliger, $15,81-87$.

Stiling, P.D. (1987) The frequency of density dependence in insect host-parasitoid systems. Ecology, $68,844-856$.
Sugiura, S., Okochi, I. \& Tamada, H. (2006) High predation pressure by an introduced flatworm on land snails on the oceanic Ogasawara Islands 1. Biotropica, 38, 700-703.

Symondson, W.O., Glen, D.M., Ives, A.R., Langdon, C.J. \& Wiltshire, C.W. (2002) Dynamics of the relationship between a generalist predator and slugs over five years. Ecology, 83, 137-147.

Thiele, H.U. (1977) Carabid Beetles in Their Environments: A Study on Habit Selection by Adaptations in Physiology and Behaviour. Translated by Joy Wieser. Springer-Verlag.

Vala, J.C., Gbedjissi, G., Knutson, L. \& Dossou, C. (2000) Extraordinary feeding behaviour in Diptera Sciomyzidae, snail-killing flies. C. R. Acad. Sci. III, Sci. Vie, 320, 299-304.

Vermeij, G.J. (1982) Unsuccessful predation and evolution. Am. Nat., 120, 701-720.

Vermeij, G.J. (1993) Evolution and Escalation: An Ecological History of Life. Princeton University Press.

Vermeij, G.J. (1995) A Natural History of Shells. Princeton University Press.

Wada, S., Kawakami, K. \& Chiba, S. (2012) Snails can survive passage through a bird's digestive system. J. Biogeogr., 39, 69-73.

Waldén, H.W. (1981) Communities and diversity of land mollusc in Scandinavian woodlands. I. High diversity communities in taluses and boulder slopes in SW Sweden. J. Conchol., 30, $351-372$.

Wang, Y., Fu, X., Lei, C., Jeng, M.L. \& Nobuyoshi, O. (2007) Biological characteristics of the terrestrial firefly Pyrocoelia pectoralis (Cleoptera: Lampyridae). Coleopt. Bull., 61, 85-93.

Wäreborn, I. (1969) Land molluscs and their environments in an oligotrophic area in southern Sweden. Oikos, 20, 461-479.

Wäreborn, I. (1970) Environmental factors influencing the distribution of molluscs of an oligotrophic area in southern Sweden. Oikos, 21, 285-291.

Wäreborn, I. (1992) Changes in the land mollusc fauna and soil chemistry in an inland district in southern Sweden. Ecography, 18, 177-180. Downloaded from Brill.com04/26/2023 10:49:40AM 
Yanes, Y., Graves, G.R. \& Romanek, C.S. (2018) Stable isotope ecology $\left(\delta_{180}, \delta_{13} \mathrm{C}, \delta_{15} \mathrm{~N}\right)$ of modern land snails along an altitudinal gradient in southern Appalachian Mountains, USA. Palaeogeogr. Palaeoclimatol. Palaeoecol., 492, 92-103.
Yom-Tov, Y. (1970) The effect of predation on population densities of some desert snails. Ecology, 51, 907-911.

RECEIVED: 22 FEBRUARY 2019 | REVISED AND ACCEPTED: 28 JUNE 2019

EDITOR: A.J. DE WINTER 